\title{
A formação do leitor crítico na aula de espanhol: a atitude curricular diante das brechas do livro didático
}

DOl: http://dx.doi.org/10.21165/el.v49i1.2478

\section{Larissa Cristina Arruda de Oliveira Benedini'}

\section{Resumo}

A formação de um leitor crítico é uma preocupação dos livros didáticos de língua estrangeira e dos documentos oficiais. E formar um leitor crítico seguindo os pressupostos do letramento crítico (CASSANY, 2006, 2010; DUBOC; 2012; MONTE MÓR, 2012, 2015, etc.) vai ao encontro dos objetivos do ensino de língua estrangeira no ensino médio integrado da Rede Federal. Neste artigo, pretende-se apresentar os resultados de um estudo de caso com professores de espanhol da Rede Federal a fim de verificar como a concepção de letramento crítico e leitor crítico dos docentes afeta suas práticas de ensino, discutir de que modo as atividades propostas pelo livro didático do PNLD LEM funcionam como brechas na formação de leitores críticos e destacar a importância da atitude curricular docente nesse processo. Para isso foi aplicado um questionário on-line e realizadas entrevistas que nos revelaram que o letramento crítico depende mais da atitude curricular do professor do que aquilo que o livro didático oferece como sugestão de trabalho e que as brechas precisam ser melhor exploradas.

Palavras-chave: letramento crítico; ensino de espanhol; leitor crítico; atitude curricular; brechas.

1 Instituto Federal de São Paulo (IFSP), Catanduva, São Paulo, Brasil; larissabenedini@gmail.com; https://orcid.org/0000-0002-3876-8926 


\title{
The formation of the critical reader in Spanish class: the curricular attitude towards textbook loopholes
}

\begin{abstract}
The formation of a critical reader is a concern of foreign language textbooks and official documents. Forming a critical reader following the assumptions of critical literacy (CASSANY, 2006, 2010; DUBOC; 2012; MONTE MÓR, 2012, 2015, etc.) meets the objectives of foreign language teaching in the integrated high school of the so-called "Rede Federal" (Federal Network). In this article, we present the results of a case study with Spanish teachers from the Federal Network in order to verify how the teachers' concept of critical literacy and critical reader affect their teaching practices. We also intend to discuss how the activities proposed by the PNLD LEM textbook work as gaps in the training of critical readers, highlighting the importance of the teaching curriculum attitude in this process. To fulfill these goals, an online questionnaire was applied and interviews were conducted, revealing that the implementation of critical literacy depends more on the teacher's curriculum attitude than on what the textbook offers as a work suggestion, proving that the gaps need to be better explored.
\end{abstract}

Keywords: critical literacy; Spanish teaching; critical reader; curriculum attitude; gaps.

\section{Introdução e objetivos}

É crescente a preocupação em formar leitores críticos no ensino básico. Isso está presente tanto nos documentos que orientam o ensino de línguas no país (BRASIL, 2006) como no livro didático do PNLD LEM (BRASIL, 2015). Por isso, é relevante desenvolver um estudo que investigue e possibilite uma melhor compreensão sobre a perspectiva do letramento crítico e a formação de leitores críticos na aula de espanhol língua estrangeira, uma vez que esses conceitos impactam desde a produção dos livros até a atuação docente. Consideramos para isso a importância das discussões teóricas sobre o conceito de letramento crítico para o ensino de línguas estrangeiras no Brasil (BAPTISTA, 2010; CASSANY, 2006; CASSANY; CASTELLÀ, 2010; COSTA, 2012; DUBOC; 2012; JORDÃO, 2010, 2015; MENEZES DE SOUZA, 2011; MONTE MÓR, 2012, 2015).

No entanto, observamos que há um descompasso entre teoria e prática na atitude curricular dos 31 professores participantes da pesquisa, o que nos motivou a investigar quais concepções sobre leitor crítico e letramento crítico embasam as práticas de ensino deste grupo de professores de espanhol da Rede Federal; quais estratégias esses professores utilizam para formar leitores críticos; quais são as brechas apontadas por esses professores em atividades do livro didático do PNLD LEM 2015 de Espanhol para o desenvolvimento da atitude curricular na formação de leitores críticos e o que as caracteriza como brechas. Portanto, são objetivos deste estudo compreender quais 
concepções sobre leitor crítico e letramento crítico são produzidas pelo campo teórico e de que forma essas concepções são apropriadas por um professor de espanhol da Rede Federal buscando identificar quais indícios em suas práticas de ensino de espanhol evidenciam a transposição dessas concepções. Além disso, analisar a atitude curricular (DUBOC, 2012)² docente nas brechas (DUBOC, 2012) do livro didático de espanhol.

Há diferentes práticas de ensino-aprendizagem que agregam o termo crítico: pensamento crítico (critical thinking), pedagogia crítica (critical pedagogy) e letramento crítico (critical literacy) são algumas delas. Há pelo menos três grandes orientações na concepção do que é ser crítico quando se fala de letramento crítico que estão relacionadas à concepção de leitura e leitor crítico: tradicional, interpretativa e crítica.

De acordo com Cassany e Castellà $(2010)^{3}$, a primeira, denominada perspectiva tradicional, baseia-se no domínio do código e concebe a leitura como a busca de um significado que está no texto. Ou seja, existe uma interpretação considerada correta, de acordo com essa visão, que está colocada ali em função da intenção do autor. O crítico, nesse caso, é concebido com um nível superior de compreensão que seria identificar a intenção do autor do texto e atingir assim a interpretação canônica.

A segunda perspectiva é chamada de interpretativa ou psicológica e é baseada nos processos cognitivos de compreensão. Aqui o leitor deve fazer uso do seu conhecimento prévio e de inferências no processo interpretativo e de construção de significado que, nesse caso, é considerado um processo interno, mental, cognitivo. Ou seja, a interpretação é uma atividade individual, por isso ler criticamente seria articular uma resposta pessoal para si mesmo.

A terceira perspectiva crítica sociocultural baseia-se na construção social do sentido do texto. Ou seja, o significado do texto emerge de contextos sociais, políticos e culturais que provocam nos leitores determinadas interpretações históricas e locais. Nessa

2 A pesquisa de Duboc (2012) se encontrará por vezes citada neste estudo uma vez que usamos
os conceitos defendidos por ela: atitude curricular e brechas. No entanto, nossa pesquisa se
diferencia desse trabalho principalmente no que se refere ao contexto investigado. Duboc (2012)
pesquisou o currículo universitário de licenciatura em inglês, enquanto nós investigamos o ensino
de espanhol no ensino médio integrado ao técnico dos Institutos Federais (IFs). Ela se debruçou
sobre a formação de professores e sua prática curricular, nós analisamos as práticas de ensino-
aprendizagem de espanhol considerando sobretudo como a concepção de leitor crítico dos
docentes envolvidos na pesquisa afeta suas práticas de ensino. Além disso, nós consideramos
o livro didático como importante instrumento de ensino que propicia as brechas na sala de aula,
enquanto ela considerou a brecha como um momento que emerge da prática.

3 Os autores afirmam terem se baseado nos estudos de Cervetti, Pardales e Damico (2001) para elaborarem essas três orientações ou concepções de letramento crítico. 
perspectiva, a ênfase está em ser crítico para compreender melhor o mundo em sua complexidade e diversidade especialmente os discursos públicos que organizam nossa sociedade. Nesse sentido, ler criticamente significa aceitar a relatividade de qualquer interpretação. Não ser dogmático, mas sim relativista e entender que há um número limitado de interpretações possíveis e válidas. É importante destacar que essas três diferentes perspectivas nos estudos de letramento emergem de diferentes concepções de leitura tendo em vista o procedimento adotado para obtenção do significado do texto.

Ainda no sentido de desfazer confusões conceituais que envolvam o termo crítico, é importante salientar as diferenças entre as concepções de letramento crítico e leitura crítica, considerando que são duas perspectivas de ensino distintas que pressupõem formar leitores críticos, uma baseada no humanismo liberal e outra em perspectivas críticas. Segundo Cervetti et al. (2001 apud DUBOC, 2012, p. 84):

\begin{abstract}
[...] o conceito de leitura crítica requer do leitor o discernimento neutro e racional entre fatos, opiniões e julgamentos pessoais, já o letramento critico prevê a multiplicidade de sentidos no texto por ser este cultural e historicamente situado, portanto, desprovido de neutralidade.
\end{abstract}

Dessa forma, enquanto a perspectiva da leitura crítica promove o desenvolvimento da habilidade de compreensão de forma racional sem considerar o caráter social e ideológico da linguagem, o letramento crítico pressupõe o desenvolvimento da consciência crítica para além da decodificação do texto, considerando questões sociais como poder, privilégio e opressão.

Nesse sentido, a proposta do letramento crítico se distancia da leitura crítica uma vez que considera tanto autor como leitor produtores de significado através da linguagem. E esses significados estão diretamente relacionados ao contexto sócio-histórico ao qual pertencem. Por isso, "o processo de ler criticamente envolve aprender a escutar não apenas o texto e as palavras que o leitor estiver lendo, mas também [...] aprender a escutar as próprias leituras de textos e palavras" (MENEZES DE SOUZA, 2011, p. 3). Concordamos com Menezes de Souza (2011) que o letramento crítico não pode mais se contentar apenas em entender como o texto está no mundo; ele precisa também entender como o texto e a leitura do texto estão com o mundo. Nesse sentido, ler criticamente envolve habilidades essenciais e distintas da leitura crítica pois:

[...] Ler criticamente implica então em desempenhar pelo menos dois atos simultâneos e inseparáveis: (1) perceber não apenas como o autor produziu determinados significados que têm origem em seu contexto e seu pertencimento sócio histórico, mas ao mesmo tempo, (2) perceber como, enquanto leitores, a nossa percepção desses significados e de seu contexto sócio histórico está inseparável de nosso próprio contexto sócio histórico e os significados que dele adquirimos. (MENEZES DE SOUZA, 2011, p. 3). 
Portanto, o leitor crítico concebido na perspectiva do letramento crítico não se limita a revelar as condições de produção do texto lido desvelando seus sentidos subjacentes e mascarados, pois, para o letramento crítico, tanto leitura quanto escrita são atos de produção de sentido pelo leitor, desse modo ele torna-se um leitor-autor. Conforme afırma Menezes de Souza (2011, p. 5): "essa acepção de letramento crítico situa a produção de significação sempre em termos do pertencimento sócio histórico dos produtores de significação, e postula tanto leitores quanto autores como igualmente produtores de significação".

Dessa forma, podemos afirmar que o aspecto fundamental que diferencia o letramento crítico da leitura crítica é a construção de significado pelo leitor no contexto de suas relações sócio históricas, rejeitando a extração de sentido do texto, defendida pela leitura crítica. Diante disso, adotar uma dessas concepções no ensino de língua estrangeira implica assumir uma perspectiva político-pedagógica no processo de desenvolvimento de letramento crítico dos alunos.

Consideramos a perspectiva crítica sociocultural nos estudos de letramento como uma das perspectivas de ensino mais adequadas para formar leitores críticos visando o desenvolvimento integral do aluno, como preconizam os documentos que orientam o ensino de línguas e os objetivos educacionais da Rede Federal.

Nesse sentido, Monte Mór (2015, p. 39) destaca a relevância da crítica nessa perspectiva de ensino: "nos recentes estudos sobre letramento, a questão da crítica se renova ao ser abordada por uma perspectiva que relaciona a linguagem como prática social". A autora ainda lembra que o letramento crítico, visto atualmente com uma proposta renovada para o ensino de linguagens, "inicia-se por rever o trabalho de leitura desenvolvido nas escolas e evolui para se disseminar como um projeto educacional" (MONTE MÓR, 2015, p. 42).

Essa perspectiva, no campo do ensino, visa desenvolver o espírito crítico e preparar os alunos para compreender discursos de diversas mídias e culturas e envolvê-los na construção dos sentidos. As Orientações Curriculares para o Ensino Médio (BRASIL, 2006) afirmam explicitamente que compete à escola formar leitores críticos e propõem que essa formação ocorra por meio de um projeto de letramento que trabalhe a linguagem (em língua materna e em línguas estrangeiras) desenvolvendo os modos culturais de ver, descrever, explicar. No que concerne à leitura, contempla pedagogicamente suas várias modalidades: a visual (mídia, cinema), a informática (digital), a multicultural e a crítica (presente em todas as modalidades). Esse documento destaca que o ensino de línguas deve 
[...] desenvolver um leitor como aquele que entende que aquilo que lê é uma representação textual, como aquele que, diante do que lê, assume uma posição ou relação epistemológica no que concerne a valores, ideologias, discursos, visão de mundo. (BRASIL, 2006, p. 98-99).

Concordamos com Cassany e Castellà (2010) que a orientação sociocultural da leitura e da escrita (ou letramento) sugere que ler e escrever não são processos cognitivos ou atos de decodificação, mas tarefas sociais, práticas culturais enraizadas historicamente em uma comunidade de falantes. Por isso, a concepção de letramento crítico que defendemos aqui está alinhada a uma prática de ensino e aprendizagem, ou seja, uma perspectiva de ensino questionadora, imbuída em questões sociais, políticas e ideológicas voltadas para uma crítica problematizadora dentro da sala de aula, ou seja, uma prática de ensino que prevê o agenciamento crítico dos alunos e sua formação cidadã.

Portanto, a importância de formar leitores críticos, capazes de avaliar discursos, contextualizar sentidos e posicionar-se criticamente diante de situações em língua estrangeira apresenta-se como relevante, o que justifica este estudo de caso que apresenta as concepções e a atitude curricular diante da brecha do livro didático de um dos docentes participante da pesquisa.

\section{Materiais e métodos}

Os instrumentos utilizados para obtenção de dados foram um questionário on-line e entrevistas individuais semiestruturadas junto a um grupo de quatro professores ${ }^{4}$ de língua espanhola dos Institutos Federais (IFs). O questionário elaborado possui um total de 39 perguntas sendo a maioria de múltipla escolha e contou com a participação de 31 professores EBTT de espanhol da Rede Federal de diferentes campi, a maioria do Instituto Federal de São Paulo - IFSP, que atuou entre os anos de 2015 e 2017 no ensino médio integrado. O questionário foi aplicado entre os meses de junho e setembro de 2018. Para a realização das entrevistas utilizamos como critério de seleção os professores que citaram no questionário as brechas dos livros didáticos do PNLD LEM 2015 que contribuíram para formar leitores críticos na aula de língua espanhola. Entre os 31 que responderam o questionário apenas 8 docentes apontaram as brechas no livro didático para formar leitores críticos (Quadro 1). No entanto, somente 4 desses professores aceitaram participar da entrevista individual. As entrevistas foram gravadas em vídeo, aconteceram em outubro de 2018 e visavam confirmar ou não as informações obtidas através do questionário sobre as concepções dos docentes e a descrição que eles fazem de sua prática de ensino neste contexto.

4 A pesquisa desenvolvida obteve aprovação do Comitê de Ética em Pesquisa (CEP), CAAE 57078116.1.0000.5504, e todos os participantes estão cientes do uso de suas respostas ao questionário para fins de pesquisa. 
Mais especificamente, buscamos compreender como esse grupo de professores enunciava suas concepções sobre o letramento crítico, quais aspectos eram enfatizados e quais atividades didáticas eram mencionadas como potenciais para o trabalho nessa perspectiva. As análises ocorreram em etapas: primeiro analisamos as concepções de letramento e leitor crítico no Guia do PNLD LEM 2015 e nas coleções aprovadas (Enlaces e Cercanía Joven), pois estes eram os livros escolhidos pelos professores da Rede Federal, depois analisamos os dados gerados através do questionário e das entrevistas. Em seguida, analisamos as brechas apontadas pelos professores no livro didático de espanhol adotado, o que as caracterizava como brechas de acordo com os pressupostos teóricos e atitude curricular docente diante daquela brecha.

As categorias de análise que utilizamos para analisar os dados obtidos foram: concepções de leitor crítico, concepções de letramento crítico, brechas apontadas pelos docentes no livro didático do PNLD LEM 2015 de língua espanhola, a atitude curricular do professor diante da brecha, as estratégias, técnicas ou os procedimentos mobilizados durante a realização das atividades citadas, a concepção sobre ensinar língua estrangeira e a perspectiva ou abordagem de ensino assumida pelo professor. Como forma de preservar a identidade dos participantes da pesquisa, utilizamos códigos para referir-se aos docentes (P1, P2 até P31). Neste artigo, realizamos um estudo de caso a partir das respostas do participante $\mathrm{P} 6$.

As análises consideraram principalmente a descrição da "atitude curricular" (DUBOC, 2012) desses docentes nas "brechas" (DUBOC, 2012) de atividades propostas pelos livros didáticos de espanhol adotados pela instituição de ensino para formação de leitores críticos na aula de espanhol como língua estrangeira a fim de confirmar nossa hipótese de que o letramento crítico depende mais da atitude do professor em sala de aula do que do livro didático adotado ou das orientações dos documentos oficiais.

O conceito de brecha, de acordo com Duboc (2012), são as oportunidades que surgem na prática pedagógica, ou seja, os momentos em que os docentes oferecem aos alunos "encontros com as diferenças" (JORDÃO, 2010) para questioná-los com o objetivo de transformar os sujeitos envolvidos naquelas práticas sociais. Sendo assim, o professor poderá encontrar as brechas para problematizar a língua e a cultura em sala de aula, basta ele aproveitar as oportunidades, pois "as brechas estão lá, na sala de aula, emergindo a qualquer instante: é a atitude docente sobre essas brechas no currículo que irá possibilitar o agenciamento crítico" (DUBOC, 2012, p. 95).

Concordamos com a definição de Duboc (2012) sobre brecha e, neste artigo, considerase como brecha todo elemento passível de desconstrução e problematização em sala de aula, partindo das atividades presentes no livro didático utilizado pelos professores como propícias para o trabalho com letramento crítico. Portanto, analisaremos de que forma essas atividades seriam problematizadoras, propícias para formação de leitores críticos e levariam à reflexão crítica do aluno. Ou seja, o que as caracteriza como uma "brecha". 
É importante salientar que as brechas estão emergindo a todo momento em sala de aula e não somente no livro didático, que neste caso foi considerado como um dos instrumentos que propiciam as brechas. Além disso, as brechas sozinhas não promovem o agenciamento crítico do aluno, elas precisam da atitude curricular docente para isso:

Assim é que concebo a atitude curricular como o combustível e a brecha como o comburente: da mesma forma que um pedaço de madeira não reage por si só sendo dependente de um meio propício (oxigênio, por exemplo) para sofrer a combustão, a atitude curricular de que falo aqui depende das brechas que emergem do próprio contexto [...] (DUBOC, 2012, p. 94).

Portanto, esses dois conceitos (brecha e atitude curricular) são indissociáveis para um trabalho à luz do letramento crítico. Ou seja, a brecha depende da atitude curricular docente para que o letramento crítico de fato ocorra. A concepção de letramento crítico como postura filosófica pautada em uma crítica problematizadora é proposta por Duboc (2012) e culmina na ideia de atitude curricular nas brechas da sala de aula, sinalizando a necessidade de mudança diante da prática curricular. A atitude não é vista como um método, mas como um processo de desconstrução no trabalho com o letramento crítico, ou seja, como um modo de leitura:

A desconstrução deve ser considerada como leitura, como um modo específico de práticas de leitura. Como tal, abarca tanto uma política quanto uma ética, entendida não tanto em termos de "método" ou "programa", mas sim como uma atitude distinta. Ou seja, a desconstrução deve ser compreendida como uma estratégia, uma atitude, uma tomada de posição diante de textos, instituições, o mundo social e o próprio ser. (GREEN, 1996 apud DUBOC, 2012, p. 95).

Concordamos com Duboc (2012) que a atitude curricular do professor é o principal ponto de partida para a prática do letramento crítico. Por isso, assumimos como pressuposto que o letramento crítico depende não somente do material didático escolhido, mas, sobretudo, da atitude docente sobre o currículo, uma vez que, conforme afirma Duboc (2012, p. 107):

[...] a crítica desejada não se encontra pronta no material didático, no professor, nos alunos ou na instituição, mas sim na relação que emerge entre todas essas instâncias cabendo ao professor praticar essa atitude problematizadora nas brechas de sua prática docente.

Consideramos as adaptações que os professores declaram realizar para adequar uma atividade ao seu contexto, os questionamentos e a problematização como atitude curricular, a preparação e a escolha de materiais didáticos além do livro do PNLD como 
vídeos, músicas, filmes relacionados ao tema da brecha e o desenvolvimento da agência do aluno. Observamos, nas respostas dos docentes entrevistados, iniciativas como discussão em grupo e problematização de temas sensíveis relacionados à realidade dos alunos, tais como, padrões de beleza, constituição familiar, consumismo, meio ambiente, discriminação e política de forma a desenvolver a autonomia e empoderamento do aluno. Dessa forma, o conceito de atitude como crítica está diretamente relacionado ao conceito de agência, pois:

[...] Agência refere-se à ação construída no processo discursivo de construção de sentidos, na produção e estabelecimento de discursos que definem e categorizam pessoas, ideias, conhecimentos e formas de conhecer. Agência é, portanto, uma forma de intervir no processo discursivo de construção de sentidos e representação do mundo. (JORDÃO, 2010, p. 423 apud DUBOC, 2012, p. 93).

O letramento crítico pode ser considerado uma forma de agência uma vez que questiona e problematiza os sentidos atribuídos ao texto influenciados por discursos e culturas dominantes, permitindo assim transformações localizadas. A noção de agência como transformação social do sujeito parte de um questionamento ou problematização em sala de aula, ou seja, de um elemento passível de desconstrução ou (re)construção de sentido que geralmente envolve estereótipos, preconceitos, hábitos etc. Sobre a agência, observamos que os alunos desenvolvem a criticidade na medida em que desconstroem paradigmas e discursos hegemônicos e os reconstroem atribuindo sentido a partir do seu contexto.

A seguir apresentaremos algumas das "brechas" identificadas em nossa pesquisa ${ }^{5}$ e discutiremos o que as caracteriza como "brechas", retomando os conceitos expostos e como dialogam com as concepções expostas anteriormente.

\section{Discussão: as brechas identificadas pelos professores}

Observamos que os docentes que identificaram a necessidade de explorar as brechas que emergem de atividades propostas pelo livro didático em geral assumiam uma atitude problematizadora a fim de desconstruir concepções e práticas que envolvem estereótipos, preconceito, exclusão, generalização, hábitos etc. Escolhemos o caso do docente P6, como exemplo de trabalho à luz do letramento crítico aproveitando as brechas do livro didático, para ilustrar essa concepção no presente artigo.

5 Esclarecemos que as brechas foram apontadas pelos professores entrevistados em atividades propostas pelos livros didáticos do PNLD LEM 2015 de Espanhol (Enlaces e Cercania Joven) para o desenvolvimento da "atitude curricular" na formação de leitores críticos. 
No questionário foi perguntado qual era a melhor atividade proposta pelo livro de espanhol do PNLD LEM 2015 que contribui para a formação de leitores críticos e solicitamos justificativa; com essa pergunta buscávamos identificar as brechas apontadas pelos professores no livro didático e analisarmos indícios em suas práticas que revelariam suas concepções de ensino. No quadro a seguir apresentamos as respostas obtidas por meio do questionário:

Quadro 1. As brechas nos livros didáticos

\begin{tabular}{|c|c|}
\hline Participante & Respostas \\
\hline P5 & $\begin{array}{l}\text { Enlaces, livro 2, p. } 60 \text { "Hablemos de..." exercícios de } 1 \text { a 7, que trata padrões de beleza. } \\
\text { Propiciou uma boa discussão em sala de aula. }\end{array}$ \\
\hline P6 & $\begin{array}{l}\text { As unidades meio ambiente e de consumismo do Enlaces } 1 \text { (atividades de interpretação e } \\
\text { de produção oral e escrita) }\end{array}$ \\
\hline P9 & $\begin{array}{l}\text { Livro 1, capítulo 5, p. } 118 \text { e } 119 \text { - para além das atividades de interpretação, essa unidade } \\
\text { sempre teve um alto impacto nas aulas, por possibilitar pontes com realidades políticas de } \\
\text { nosso país e outros, no caso, como o Chile. Livro 2, capítulo 1, p. } 17 \text { a } 19 \text { - para além das } \\
\text { atividades de interpretação é possível romper com determinados "pré- conceitos" existentes } \\
\text { sobre o Paraguai. }\end{array}$ \\
\hline P11 & $\begin{array}{l}\text { Pág. } 105 \text { volume } 2 \text { Cercania Joven Reflexion Texto Rotundamente Negra Shirle Campbell } \\
\text { pág. 106, 107, } 108 \text { Em cabelo de Illari }\end{array}$ \\
\hline P16 & $\begin{array}{l}\text { Há uma atividade, em especial, que gostei muito que fala de um club de leitura de estudantes } \\
\text { argentinos de Buenos Aires. Fala sobre acoso escolar, diversidad etnico-racial e sobre a } \\
\text { perspectiva do estudante diante da realidade da escola. Enlaces, livro 1, Unidade } 7\end{array}$ \\
\hline P20 & $\begin{array}{l}\text { Lembro-me de uma atividade do Enlaces livro 2, sobre constituição de famílias. A discussão } \\
\text { que pode ser promovida é interessante. }\end{array}$ \\
\hline P26 & $\begin{array}{l}\text { A melhor atividade proposta pelo livro Cercanía Joven, na minha opinião, intitula-se "Culturas } \\
\text { en diálogo: nuestra cercanía. La dictadura en el cine latinoamericano: a hacer una tertulia!"; } \\
\text { está no livro primeiro, páginas 152-153. A atividade é interessante, posto que leva o aluno a } \\
\text { refletir sobre um determinado momento histórico-social (a ditadura na América latina) por } \\
\text { meio de filmes e, ao mesmo tempo, usar a língua, que, por sua vez, espelha uma prática } \\
\text { discursiva, característica esta pertencente ao letramento crítico. }\end{array}$ \\
\hline P31 & Livro 2 Cercanía Joven, página 35. Gosto muito das seções de projetos também. \\
\hline
\end{tabular}

Fonte: Elaboração própria

É importante destacar que dos 31 professores participantes da pesquisa apenas 8 apontaram atividades específicas do livro didático que consideram como brechas para formar leitores críticos. Quanto aos demais participantes, cinco afırmaram não usar o livro didático do PNLD LEM 2015, 11 docentes apontaram atividades genéricas sem referência 
de página ou unidade do livro didático, apenas citando temas como gêneros textuais, questões culturais e a seção de projetos do livro e sete participantes disseram que não se lembravam, não estavam com o livro no momento ou não souberam responder.

De forma geral, as respostas dos 8 participantes que indicaram atividades específicas dos livros didáticos como brechas para a atitude curricular focalizam "discussão", "interpretação" e "reflexão", além de implicarem temas políticos e sociais na aula de língua espanhola. Levando em consideração os objetivos do presente artigo, optamos por realizar um recorte dos dados e aprofundaremos a discussão sobre a resposta do participante P6. As atividades apontadas por P6 no livro didático como propícias para formar leitores críticos ${ }^{6}$ envolvem os temas consumismo e meio ambiente. Analisaremos a brecha apontada por P6 no livro didático Enlaces volume 1 a qual faz parte da unidade cujo tema é preservação do meio ambiente (OSMAN et al., 2013, p. 79), a partir do excerto abaixo:

Na unidade do meio ambiente eu levei duas músicas ${ }^{7}$ que falavam sobre meio ambiente, a primeira tinha umas imagens bonitas de natureza, usei antes de começar a unidade para ativar os conhecimentos prévios, a segunda o vídeo trazia imagens bem chocantes do meio ambiente, tipo um pinguim com óleo, 0 esgoto sendo jogado no mar. Eu lembro que eu discuti a música com eles, fiz um debate oral sobre a música depois de ler o texto. Trabalhamos também o texto e as atividade de interpretação de texto (p. 84-85). No vídeo "Puedes cambiar el mundo" eles tinham que identificar o problema, nomear todos esses problemas de meio ambiente do vídeo. Eles sentaram para fazer um debate coletivo escolhendo um dos problemas citados e criarem estratégias para resolver aquele problema. Eles tinham que fazer uma exposição oral depois com essas estratégias. Fizemos um folheto com oito ou dez dicas de como resolver os problemas usando o imperativo. Ficamos umas duas aulas fazendo essa atividade. Saímos do livro. A gente colou os cartazes que eles fizeram na escola com dicas sobre meio ambiente de como resolver aqueles problemas. (Trecho de entrevista com P6, grifo nosso).

Observamos que a atividade citada por P6 parte do gênero textual notícia de jornal (ver Anexos), nesse caso a fonte é BBC Colômbia, e foi dividida em 6 parágrafos, todos numerados, para facilitar a localização de informações por parte do aluno. Nota-se que a questão (a) pede que o aluno deduza, ou infira a partir da sua leitura do texto o que significa "despertar ecológico". Ou seja, é a uma questão de compreensão leitora que faz

6 As imagens das atividades encontram-se nos Anexos para consulta.

7 "Hermana tierra" de Laura Pausini (disponível em: https://www.youtube.com/ watch?v=m35BIIdrS-Q) e "Puedes cambiar el mundo" (disponível em: https://www.youtube.com/ watch?v=8Yirl_bVSGM) de Alejandro Lerner. 
uso da inferência. A questão (b) é uma atividade de localização de informação explícita no texto na qual o aluno deve procurar a profissão da autora do texto e uma frase que comprove isso. As questões (c) e (d) também são de localização de informação explícita no texto. Assim como a questão (e) que pede para o aluno transcrever a resposta do texto. A questão (f) é uma questão de informações pessoais na qual o aluno deve dizer se as pessoas ao seu redor se preocupam com o meio ambiente e quais atitudes elas têm. A questão (g) também é de informações pessoais na qual o aluno deve opinar se todos contribuem da mesma forma para emissão de gases contaminantes. A última questão (h) também está relacionada a informações pessoais, seria uma espécie de confissão por parte do aluno sobre suas atitudes em relação ao meio ambiente.

Concordamos com Costa (2012) que as questões de resposta pessoal dão destaque ao tema e deixam à margem os aspectos que configuram o texto como prática social, envolvendo locutores, interlocutores, contextos, propósitos, funções e ideologias. Além disso, acreditamos que manifestar opinião sobre o tema do texto e falar sobre a própria realidade sem problematização não são estratégias relevantes na formação de leitores críticos. 0 estudante deve ter oportunidade de ampliar sua reflexão quando expressa sua opinião livremente, discutindo, por exemplo, por que pensa daquela forma com determinadas crenças e julgamentos. Não observamos nenhuma questão problematizadora que leve o aluno a questionar seus hábitos e refletir criticamente sobre as consequências disso para o meio ambiente. Observamos, nesses exercícios do livro didático Enlaces, uma concepção de leitura linguística e algumas vezes psicolinguística. Portanto, essas questões não contribuem significativamente para formação de leitores críticos, da forma como estão sugeridas no livro didático. Nesse caso, esse objetivo para ser realizado vai depender da atitude curricular do professor diante dessa brecha, conforme mostraremos a seguir.

\section{Análise da atitude curricular docente diante das brechas}

Sobre a atitude curricular docente diante da brecha apontada no livro didático destacamos a iniciativa de buscar material complementar. A promoção do debate sobre o tema em pequenos grupos para identificar os problemas ambientais expostos no vídeo e a criação de estratégias para resolução dos problemas. Notamos, portanto, a atitude problematizadora do docente diante da brecha para discutir o tema meio ambiente a fim de levar os alunos a questionarem suas próprias atitudes. Isso significa que os alunos deveriam posicionar-se criticamente ao avaliarem as consequências ambientais expostas no vídeo.

Depois disso, o docente ainda sugeriu que os alunos em grupos trabalhassem o gênero folheto, produzindo folhetos que seriam colocados na escola para conscientizar toda a comunidade sobre suas ações em relação ao meio ambiente. Portanto, destacamos a preocupação do docente em conscientizar a comunidade e transformar seu contexto social. As atividades realizadas pelo docente a partir da brecha sobre meio ambiente nos 
levam a considerar que não se trata de aula tradicional de leitura, atrelada aos aspectos estritamente formais e de conteúdo gramatical. Isso significa que o docente promoveu na aula a exposição aos mais diversos textos (visual e verbal) para que o aluno refletisse sobre eles e os avaliasse, tendo em vista os desdobramentos disso em sua vida social.

Poder-se ampliar a proposta do docente com a realização de projetos interdisciplinares aliados às disciplinas de Biologia e Geografia, por exemplo, para aprofundamento do tema e promover a integração do currículo conforme se espera no ensino médio integrado. Se possível, promovendo debates e ciclos na escola em torno do tema meio ambiente. Os alunos também poderiam gravar vídeos em espanhol em pequenos grupos sobre as iniciativas sustentáveis em sua comunidade para contribuir com o meio ambiente e divulgá-las nas redes sociais a fim de influenciarem digitalmente outros colegas além de praticarem a oralidade.

Perguntamos ao docente P6 na entrevista se ele considera seus alunos leitores críticos em LE e como ele avalia a aprendizagem dos alunos e obtivemos a seguinte resposta:

O nosso leitor em língua em espanhola eu acho que é o mesmo leitor em língua portuguesa, não vejo muita diferença, desde o primeiro ano. Por que o espanhol é muito próximo, o léxico do espanhol é muito semelhante. Eu acho que os alunos conseguem entender o texto. São poucas palavras que causam dificuldade para eles, conseguem desvendar as informações explícitas. A dificuldade de fazer inferências, estabelecer intertextualidade é a mesma em língua portuguesa. Até quando vem um pai e fala que vai tirar o filho do espanhol porque está com dificuldade eu digo que o espanhol está reforçando as competências de leitura e escrita. Porque o que a gente faz é dar um repertório sociocultural maravilhoso que ele vai poder usar na redação, na vida, para interpretar textos diversos, é o que vai ser cobrado no ENEM dele. Os alunos do terceiro ano são aqueles que vão fazer a prova do ENEM em espanhol. Eu acho que o que deixa o aluno menos crítico é a falta de informação, porque eles não leem. No Enlaces não tinha esse tipo de preocupação. (Trecho da entrevista com P6, grifo nosso).

Observamos a partir da resposta de P6 na entrevista que esse participante não considera seus alunos leitores críticos tendo em vista a leitura na perspectiva crítica sociocultural. De acordo com as palavras-chave que destacamos no trecho da entrevista, o docente considera que seus alunos têm uma leitura puramente linguística tanto em língua portuguesa como em língua estrangeira, ou seja, eles conseguem entender o texto a partir das regras de combinação e unidade léxicas, desvendando as informações explícitas somente. No entanto, não são capazes de fazer inferências e estabelecer relações de intertextualidade, segundo o docente. 
Portanto, não se constituem como leitores críticos em uma concepção sociocultural de leitura. Chamamos a atenção também para o fato de que P6 considera a informação adquirida através da leitura um elemento importante na constituição do leitor crítico, assim como o repertório sociocultural. Tendo em vista os elementos destacados na fala, podemos afirmar que a concepção do docente de leitor crítico de P6 se aproxima da psicolinguística, pois considera que ele deve ser capaz de fazer inferências e usar seu conhecimento prévio para estabelecer relações de intertextualidades.

Transcrevemos abaixo outro trecho da entrevista com P6 no qual revela sua opinião sobre o letramento crítico, proposta teórica assumida pelo livro Sentidos PNLD 2018, o qual o docente afirma usar atualmente, o que também nos releva um pouco sobre sua concepção de letramento crítico:

Eu estou gostando dessa nova metodologia proposta pelo livro didático novo [Sentidos], mas inicialmente foi um choque, um aluno me disse: 'mas professora quando a gente vai ver matéria? Pois só lemos texto...' Há 11 anos quando eu estava faculdade eu lembro que tinha aquela questão comunicativa sabe, totalmente diferente dessa nova proposta, vejo que essa proposta é assim muito gênero textual, que é uma coisa nova em linguística aplicada, é legal, eu acho que a gente tem que desenvolver a leitura do aluno, só que falta pra mim, algumas coisas mais assim não tão cansativas, o tipo de texto, o gênero que eles escolhem... tem algumas unidades que não são cansativas, por exemplo, monólogo de humor, eles adoraram, quando é um gênero assim mais divertido ou curto... Mas, quando você pega uma unidade como aquela de carta institucional, nossa, super cansativo. Um tema que eles não têm interesse, eles querem morrer... o que eu tenho feito é levado vídeos, música, imagem, pintura, para começar a aula. Senão fica muito parecido com a aula de português... só texto... eu sinto falta de discutir mais a língua, aspectos da língua e da cultura, entendeu? Parecia que os Enlaces era menos cansativo por conta da diversidade das atividades, de escuta, etc. o que está maçante é a quantidade de interpretação de texto. (Trecho da entrevista com P6, grifo nosso).

A partir da resposta observamos que a concepção de letramento crítico do docente P6 está relacionada ao trabalho com gêneros textuais, sobretudo o texto escrito, o qual julga cansativo e maçante devido à quantidade de atividades de leitura e interpretação de texto contidas no livro Sentidos PNLD 2018, o qual assume o letramento crítico como orientação teórica.

Ou seja, percebemos que sua concepção de letramento crítico vem da leitura que fez sobre o livro didático do PNLD que utiliza em sala de aula. E essa concepção se confirma quando comparamos com sua resposta no questionário sobre o que entende por letramento crítico: "nunca li nada a respeito. Quando estudei linguística aplicada a abordagem 
comunicativa estava em voga". No entanto, percebemos ao longo da entrevista que o docente buscou conhecimento para transformar a sua prática, ciente da necessidade de atualização e formação continuada dos professores de LE e do papel que esses desempenham na sociedade atual:

\begin{abstract}
Eu nunca tinha escutado falar nesse tipo de abordagem quando estava na graduação ou pós-graduação, foi falando com você que descobri porque estava em crise. E todos os livros do PNLD 2018 tinham essa mesma abordagem. Eu ainda estava na abordagem comunicativa. Era diferente. Eu fazia antigamente avaliação só oral. Hoje, eu não dou mais o peso que eu dava para as quatro habilidades separadamente. Agora o que tento desenvolver mesmo é promover o debate para o aluno ficar mais crítico. E sinceramente eu acho que é o ideal mesmo, na realidade que a gente está vivendo.... essa habilidade de ser crítico para o mundo de pensar o mundo sem ser manipulado é muito mais importante para o nosso aluno de escola pública que não teve contato com cultura, com esse repertório todo. (Trecho da entrevista com P6, grifo nosso).
\end{abstract}

Apesar de algumas falas de P6 darem indícios de um ensino mais comunicativo, com conceitos, no princípio, que não condiziam com a perspectiva do letramento crítico, conforme destacamos anteriormente, notamos que existe um esforço por parte do docente em integrar as perspectivas de ensino para atingir os objetivos propostos. Sobretudo, porque procurou se aprofundar na teoria do letramento crítico e em dar voz aos alunos trazendo o conhecimento prévio dos alunos para dentro da sala de aula, conforme demonstrado no trecho a seguir: "[...] estava tendo dificuldade de aceitação deste novo material didático [Sentidos]. Eu entrei em crise. Então eu fui pesquisar sobre esse novo material, para ter conhecimento sobre ele, pra acreditar naquilo que eu estou fazendo. [...]" (Trecho de entrevista com P6, grifo nosso).

Embora haja esse esforço por parte do docente em atualizar seus conhecimentos e modificar sua prática de ensino, é importante destacar que sua abordagem declarada de ensinar é "gramatical-comunicativizada", conforme resposta dada no questionário, o que reforça a mistura de concepções e teorias em sua prática de ensinar língua estrangeira.

Sobre as atividades de leitura na aula de espanhol para formar leitores críticos, o docente revela quais estratégias, técnicas e recursos são mobilizados nesse processo:

Eu não trago mais texto. $\mathbf{O}$ que eu trago são vídeos. Eu gosto muito de trabalhar com imagens, música também, esse tipo de coisa. Normalmente eu deixo eles lerem sozinho. Se o texto for muito difícil, destacarem as palavras que eles não conhecem, buscarem na internet essas palavras e aí a gente lê de novo em voz alta, para trabalhar a questão oral, comentando as palavras que eles não conhecem e aí a gente vai para as questões de interpretação de texto. Depois 
a gente corrige. Tem uma coisa que o livro faz que é trazer o texto dividido em parágrafos com número. Tem hora que dá certo mas tem hora que não. (Trecho de entrevista com P6, grifo nosso).

Nesse trecho da fala de P6 destacamos as estratégias mobilizadas em atividades de leitura: leitura em voz baixa, buscar palavras novas no texto, leitura em voz alta, responder questões "interpretativas" e correção. Esses recursos mobilizados dão indícios de uma concepção tradicional de ensinar e aprender língua e vão ao encontro da abordagem declarada pelo docente "gramatical-comunicativizada". Não há menção na entrevista de P6 sobre os novos modos de leitura e escrita usando a internet, tampouco procedimentos como reflexão crítica, construção social do sentido do texto e expressões de relações de poder, características de uma perspectiva sociocultural de letramento crítico.

Observamos que, de forma geral, sua perspectiva de ensino estava mais centrada na língua (gramática e vocabulário), na qual o docente exerce um papel de informador, orientador e sistematizador básico. Notamos também que sua concepção de aprender língua estava relacionada a reter informações e desenvolver habilidades. Nesse caso, o que sugerimos não é a substituição de uma concepção de leitor crítico ou abordagem de ensinar por outra, mas a incorporação de novas perspectivas que contribuam para o desenvolvimento da percepção crítica do aluno. Ressaltamos que todas as atividades do livro didático são importantes para a formação do aluno de alguma forma, embora apresentem concepções de leitura diferentes, pois as concepções se complementam.

\section{Conclusões}

Os resultados alcançados com as análises confirmaram nossa hipótese de que a implementação do letramento crítico, tal como proposto no campo teórico, depende mais da atitude curricular do professor do que aquilo que o livro didático ou os documentos curriculares oferecem como sugestão de trabalho. Concluímos que alguns professores trabalham as atividades propostas pelos livros sem aproveitar completamente as brechas que poderiam permitir a formação do leitor crítico em língua espanhola. Também observamos, a partir dos resultados obtidos, que há necessidade de maior esclarecimento quanto à perspectiva de ensino do letramento crítico e a concepção de leitor crítico entre os docentes de espanhol dos Institutos Federais de Educação, Ciência e Tecnologia para que de fato esses princípios teóricos estejam presentes em suas práticas de ensino. $\mathrm{E}$ concluímos também que é possível realizar um trabalho à luz do letramento crítico e formar leitores críticos na aula de língua estrangeira a partir das brechas do livro didático. Acreditamos que a opção pelo letramento crítico como perspectiva de ensino de língua espanhola, integrada ou não à outra abordagem de ensinar, seja um dos caminhos possíveis para o desenvolvimento da criticidade nos alunos e que esta seria a filosofia de ensino que mais se adéqua aos princípios defendidos pela própria Rede Federal no Brasil. 


\section{REFERÊNCIAS}

BAPTISTA, L. M. T. R. Traçando caminhos: letramento, letramento crítico e ensino de espanhol. In: BARROS, C. S.; COSTA E. G. M. (ed.). Espanhol: ensino médio. Coleção explorando o ensino. Brasília, Brasil: Ministério da educação, Secretaria da Educação. 2010. p. 119-136.

BRASIL. Guia de Livros Didáticos: PNLD 2015 - Língua Estrangeira. Brasil, Brasília: Ministério da Educação, Secretaria de Educação Básica, 2015. Disponível em: http:// www.fnde.gov.br/programas/programas-do-livro/livro-didatico/guia-do-livro-didatico/ item/5940-guia-pnld-2015. Acesso em: 01 jun. 2018.

BRASIL. Orientações curriculares para o ensino médio. Linguagens, códigos e suas tecnologias. Conhecimentos de Línguas Estrangeiras. Brasil, Brasília: MEC, Secretaria de Educação Básica, 2006. p.127-164. Disponível em: http://www.portal.mec.gov.br/seb/arquivos/pdf/ book_volume_01_internet.Pdf. Acesso em: 01 jun. 2018.

CASSANY, D. Tras las líneas. Sobre la lectura contemporánea. Barcelona: Anagrama, 2006.

CASSANY, D.; CASTELLÀ, J. Aproximación a la literacidad crítica. PERSPECTIVA, Florianópolis, v. 28, n. 2, 353-374, jul./dez. 2010.

CERVETTI, G.; PARDALES, M. J.; DAMICO, J. S. A Tale of Differences: Comparing the Traditions, Perspectives, and Educational Goals of Critical Reading and Critical Literacy. Reading Online, v. 4, n. 9, 2001. Disponível em: http://www.readingonline.org/articles/art_ index.asp?HREF=/articles/cervetti/index.html. Acesso em: 20 fev. 2018.

COSTA, E. G. de M. Práticas de letramento crítico na formação de professores de línguas estrangeiras. Revista Brasileira de Linguística Aplicada, Belo Horizonte, v. 12, n. 4, p. 911 932, 2012.

DUBOC, A. P. M. Atitude curricular: letramento crítico nas brechas da formação de professores de inglês. 2012. Tese (Doutorado em Estudos Linguísticos e Literários em Inglês) - Faculdade de Filosofia, Letras e Ciências Humanas, Universidade de São Paulo. São Paulo, 2012.

FREITAS, L. M. A.; COSTA, E. G. M. Sentidos en la lengua española. São Paulo: Richmond, 2016.

FOUCAULT, M. A ordem do discurso. 19. ed. São Paulo. Loyola, 2009 [1971]. 
JORDÃO, C. M. A posição do professor de inglês no Brasil: hibridismo, identidade e agência. Rev. Letras \& Letras, v. 26, n. 2, p. 427-442, jul./dez. 2010.

JORDÃO, C. M. Abordagem comunicativa, Pedagogia crítica e Letramento Crítico - farinha do mesmo saco? In: HILSDORF, C.; MACIEL, R. (org.). Língua Estrangeira e Formação Cidadã: por entre discursos e práticas. Coleção: Novas Perspectivas em Linguística Aplicada v. 33. 2. ed. Campinas: Pontes, 2015.

MENEZES DE SOUZA, L. M. Para uma redefinição de letramento crítico: conflito e produção de significação. In: MACIEL, R.; ARAÚJJ, V. (ed.). Formação de Professores de Línguas: ampliando perspectivas. Publisher: Paco Editorial, 2011. p. 328.

MONTE MÓR, W. O ensino de línguas estrangeiras e a perspectiva dos letramentos. In: BARROS, C. S.; COSTA, E. G. M. (org.). Se hace el caminho al andar: reflexões em torno do ensino de espanhol na escola. Belo Horizonte: Faculdade de Letras da UFMG, 2012.

MONTE MÓR, W. Crítica e letramentos críticos: reflexões preliminares. In: ROCHA, C. H.; MACIEL, R. F. (org.). Língua estrangeira e formação cidadã: por entre discursos e práticas. Coleção Novas Perspectivas em Linguística Aplicada. v. 33. 2. ed. Campinas: Pontes, 2015.

OSMAN, S. et al. Enlaces. São Paulo: Macmillan, 2013. 


\section{ANEXOS}

6. Ahora lee el siguiente artículo de opinión y contesta las preguntas.

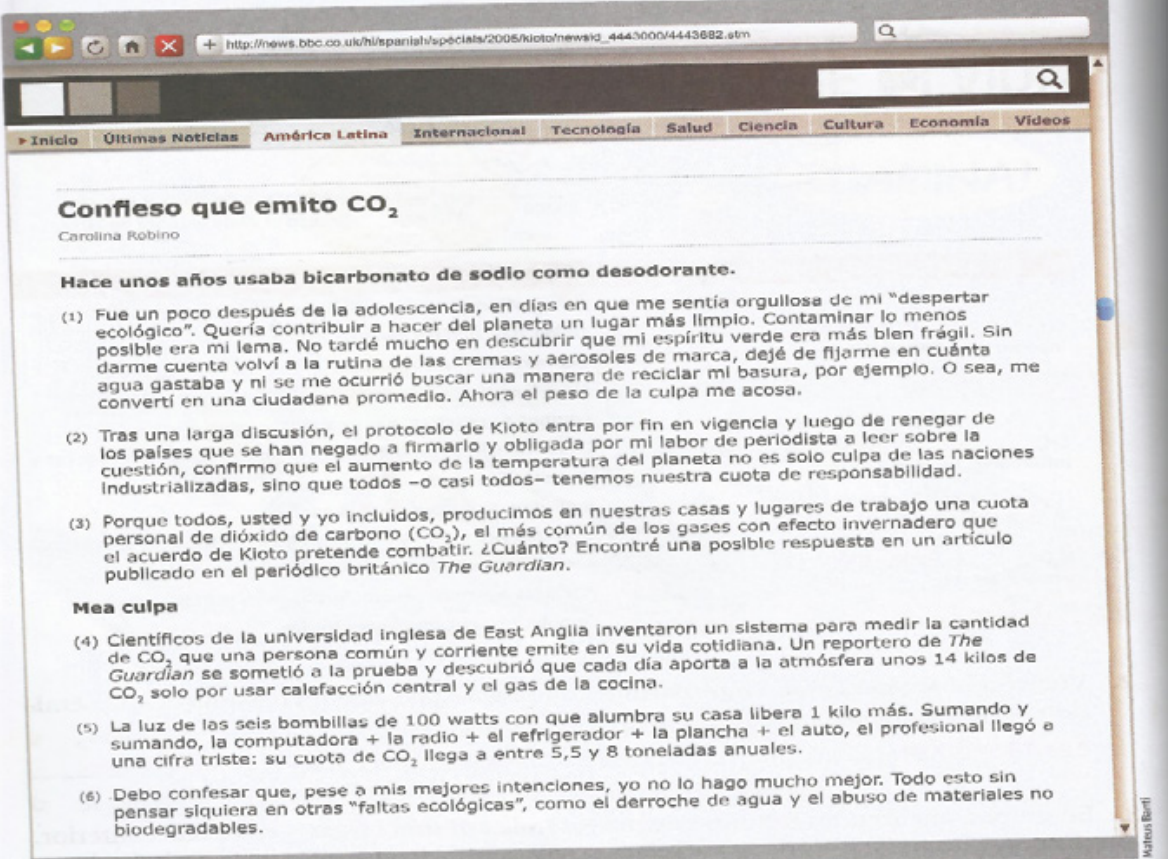

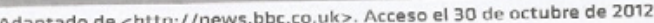

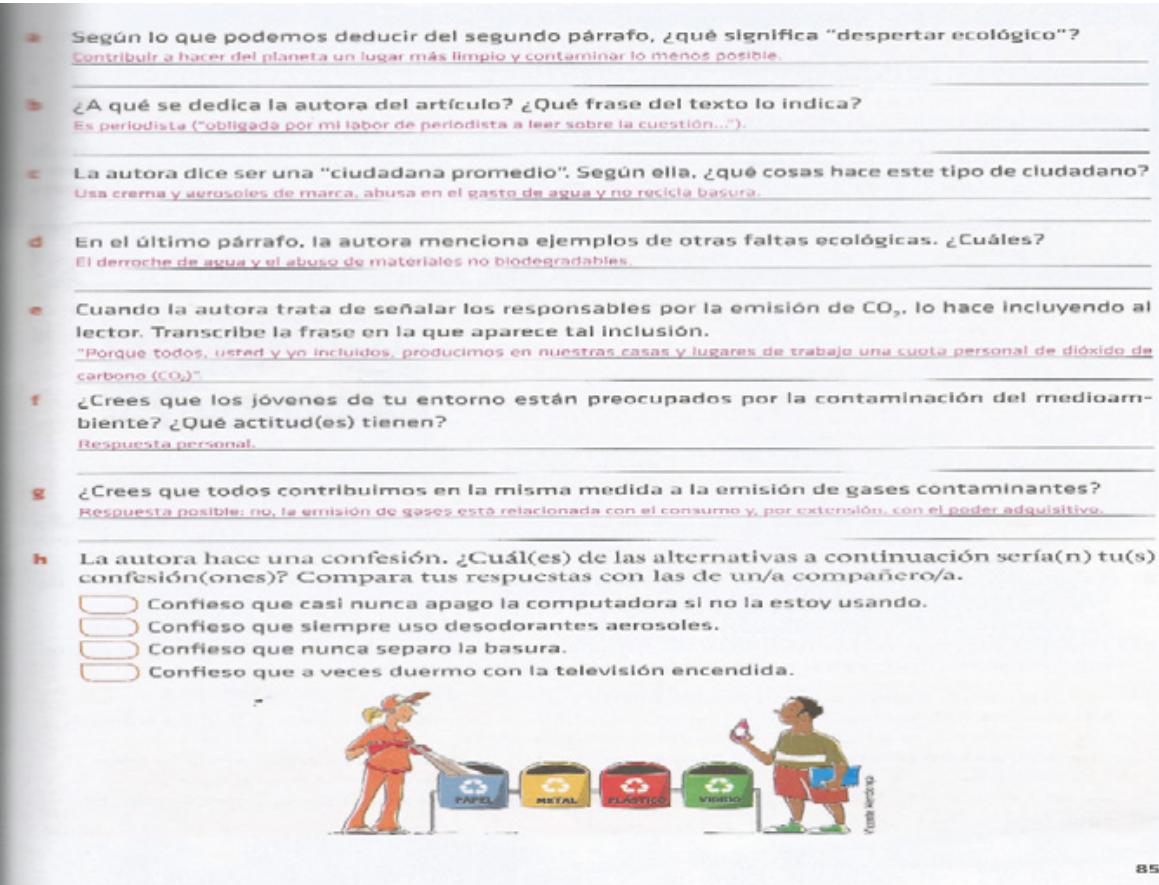

